\title{
Anabolic and catabolic responses of human articular chondrocytes to varying oxygen percentages
}

\author{
Simon Ströbel ${ }^{1}$, Marko Loparic ${ }^{1,2}$, David Wendt ${ }^{1}$, Andreas D Schenk ${ }^{2}$, Christian Candrian ${ }^{1,3}$, Raija LP Lindberg ${ }^{4}$, \\ Florina Moldovan ${ }^{5}$, Andrea Barbero ${ }^{1 *}$, Ivan Martin ${ }^{1}$
}

\begin{abstract}
Introduction: Oxygen is a critical parameter proposed to modulate the functions of chondrocytes ex-vivo as well as in damaged joints. This article investigates the effect of low (more physiological) oxygen percentage on the biosynthetic and catabolic activity of human articular chondrocytes (HAC) at different phases of in vitro culture.

Methods: HAC expanded in monolayer were cultured in pellets for two weeks (Phase I) or up to an additional two weeks (Phase II). In each Phase, cells were exposed to 19\% or 5\% oxygen. Resulting tissues and culture media were assessed to determine amounts of produced/released proteoglycans and collagens, metalloproteinases (MMPs), collagen degradation products and collagen fibril organization using biochemical, (immuno)-histochemical, gene expression and scanning electron microscopy analyses. In specific experiments, the hypoxia-inducible factor-1 $\alpha$ (HIF-1 $\alpha$ ) inhibitor cadmium chloride was supplemented in the culture medium to assess the involvement of this pathway.

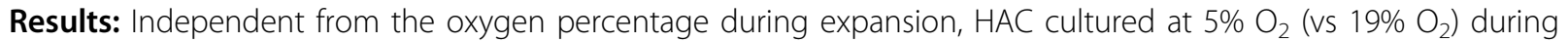
Phase I accumulated higher amounts of glycosaminoglycans and type II collagen and expressed reduced levels of MMP-1 and MMP-13 mRNA and protein. Switching to 19\% oxygen during Phase II resulted in reduced synthesis of proteoglycan and collagen, increased release of MMPs, accumulation of type II collagen fragments and higher branching of collagen fibrils. In contrast, reducing $\mathrm{O}_{2}$ during Phase II resulted in increased proteoglycan and type II collagen synthesis and reduced expression and release of MMP-13 mRNA and protein. Supplementation of cadmium chloride during differentiation culture at $5 \% \mathrm{O}_{2}$ drastically reduced the up-regulation of type II collagen and the down-regulation of MMP-1 mRNA.
\end{abstract}

Conclusions: The application of more physiologic oxygen percentage during specific phases of differentiation culture enhanced the biosynthetic activity and reduced the activity of catabolic enzymes implicated in cartilage breakdown. Modulation of the oxygen percentage during HAC culture may be used to study pathophysiological events occurring in osteoarthritis and to enhance properties of in vitro engineered cartilaginous tissues.

\section{Introduction}

Homeostasis of normal cartilage in adults represents a delicate balance between the synthesis and the degradation of extracellular matrix components to maintain the functional integrity of the joint. In elderly individuals, together with changes in proliferation activity, energy metabolism and response to growth factors [1],

\footnotetext{
*Correspondence: abarbero@uhbs.ch

'Departments of Surgery and of Biomedicine, University Hospital Basel, Hebelstrasse 20, Basel, 4031, Switzerland
}

chondrocytes become less resistant to extrinsic stress. This in turn causes a disturbance of tissue homeostasis and thus the risk of degenerative pathologies of osteoarthritic nature [2]. In particular the oxidative stress is proposed to play a key role in cartilage degeneration.

Oxygen is a critical parameter proposed to modulate chondrocyte metabolic activity [3]. Indeed, articular cartilage is generally exposed to a finely regulated gradient of relatively low oxygen percentages (from about $10 \%$ at the surface to about $1 \%$ in the deepest layers) [4], which 
is essential for maintenance of specialized tissue function [5]. During the onset of cartilage degeneration, possibly due to surface fibrillation and/or microfractures of the subchondral bone, such gradients have been proposed to break down [6], thus contributing to the progression of the disease.

The influence of various oxygen percentages on chondrocyte function has been investigated in a broad variety of models, differing with respect to (i) the cell source used (species: bovine, chicken, rodents, human, and anatomical locations of cell harvesting: knee, hip, interphalangeal joint, nose), (ii) the characteristic of the donor (age, stage of cartilage degeneration), (iii) the oxygen percentage applied (from less then 1\% to more than $60 \%$ ), (iv) the hydrodynamic culture conditions (static culture or mixing within bioreactors), and (v) the stage of cell differentiation (cells in native tissue, de-differentiated cells, re-differentiating expanded cells in pellets, alginate gels, or different types of porous scaffolds). It is thus not surprising that the data reported in literature on the influence of oxygen percentage on chondrocyte behavior are rather controversial [3]. For instance, as compared to culture under normoxic conditions (18 to $21 \%$ oxygen), culture at more physiological, low oxygen percentages ( 1 to $8 \%$ ) has been reported to increase [7-10], decrease $[11,12]$ or have no effect on the chondrocyte proliferation rate [6,13-15]. Moreover, the expression of cartilage specific genes and/or the extent of matrix protein synthesis/deposition was reported to be up-regulated [6-9,12,15-22], down-regulated $[10,23-26]$ or not modulated at all $[6,9]$ by culture under more physiological oxygen percentages.

Importantly, in addition to the still controversial findings, in the above mentioned studies the effect of oxygen percentage on chondrocytes has mainly been investigated with regard to the cell biosynthetic activity, without considering and exploring chondrocyte catabolic processes. We thus aimed our study at investigating the effect of a low (more physiological) oxygen percentage both on the cartilage tissue forming capacity of human articular chondrocytes (HAC), and on their pro-catabolic, matrix degradative activity. In particular, we hypothesized that culture at a more physiological oxygen percentage has a dual role in the chondrocyte metabolism, by enhancing their biosynthetic activity and at the same time reducing the expression of matrix degradative enzymes. To test these hypotheses, HAC were exposed to normoxic conditions (19\%) or to a low oxygen percentage (5\%) during culture in two simple and widely used model systems (that is, monolayer expansion or differentiation in micromass pellets), as well as at different phases of tissue development (that is., during denovo tissue formation or in pre-formed tissues). We further investigated whether the applied oxygen percentage influences the structural organization of the collagen fibrils produced by HAC and whether those features have a pathophysiological counterpart in healthy and osteoarthritic cartilage tissue. Finally, in order to address whether the metabolic effects of HAC culture at low oxygen percentage involve signaling through the hypoxia-inducible factor- $1 \alpha$ (HIF-1 $\alpha$ ) pathway, some cultures were supplemented with the specific inhibitor cadmium chloride.

\section{Materials and methods \\ Cartilage samples collection}

Macroscopically normal human articular cartilage samples (Mankin Score: 2 to 3) were obtained post mortem (within 24 hours after death) from the knee joints of a total of six donors with no clinical history of joint disorders (mean age: 56 years, range: 43 to 65 years), after informed consent by relatives and in accordance with the local ethics committee (University Hospital Basel, Switzerland). Cells from different donors were used for independent experimental runs. Osteoarthritic cartilage tissues (Mankin Score: 6 to 7) harvested from three patients undergoing total or partial knee replacement (female:male $=2: 1$, mean age: 67 years, range 65 to 71 years) were used as controls for degenerated structural organization of collagen fibrils.

\section{Chondrocyte isolation and expansion}

Cartilage tissues were minced in small pieces and digested with $0.15 \%$ type II collagenase $(10 \mathrm{ml}$ solution $/ \mathrm{g}$ tissue) for 22 hours. The isolated human articular chondrocytes (HAC) were expanded for two passages with Dulbecco's Eagle's Medium (DMEM) containing $4.5 \mathrm{mg} /$ $\mathrm{ml}$ D-glucose, $0.1 \mathrm{mM}$ nonessential amino acids, $1 \mathrm{mM}$ sodium pyruvate, $100 \mathrm{mM}$ HEPES buffer, $100 \mathrm{U} / \mathrm{ml}$ penicillin, $100 \mu \mathrm{g} / \mathrm{ml}$ streptomycin and $0.29 \mathrm{mg} / \mathrm{ml}$ L-glutamate supplemented with $10 \%$ of foetal bovine serum (complete medium) and $1 \mathrm{ng} / \mathrm{ml}$ of Transforming Growth Factor $\beta 1$ (TGF $\beta-1), 5 \mathrm{ng} / \mathrm{ml}$ of Fibroblast Growth Factor 2, and $10 \mathrm{ng} / \mathrm{mL}$ of Platelet-Derived Growth Factor-BB (all from R\&D Systems, Minneapolis, MN, USA) (expansion medium) [27] in a humidified incubator $\left(37^{\circ} \mathrm{C} / 5 \% \mathrm{CO}_{2}\right)$ at either normoxic condition $\left(19 \% \mathrm{O}_{2}\right)$ or low, more physiological oxygen tension $(5 \%$ $\mathrm{O}_{2}$ ). Expansion medium was equilibrated under $5 \%$ and $19 \% \mathrm{O}_{2}$ for at least six hours before each media change. Expanded cells were subsequently cultivated in pellets as described below.

\section{D pellet cultures}

The chondrogenic capacity of expanded HAC was investigated in pellet cultures under the two oxygen conditions $\left(19 \% \mathrm{O}_{2}\right.$ and $\left.5 \% \mathrm{O}_{2}\right)$ used for the expansion. Chondrocytes were re-suspended in complete medium 
supplemented with $10 \mu \mathrm{g} / \mathrm{ml}$ insulin (ACTRAPID HM), $0.1 \mathrm{mM}$ ascorbic acid 2-phosphate (SIGMA, San Gallen, Switzerland), $10 \mathrm{ng} / \mathrm{mL}$ Transforming Growth Factor- $\beta 3$ (Novartis, Basel, Switzerland) (chondrogenic medium) [27]. Chondrogenic medium was equilibrated under 5\% and $19 \% \mathrm{O}_{2}$ for at least six hours before each media change.

Pellets generated by cells from two donors after two weeks of culture under the two oxygen percentages $\left(19 \% \mathrm{O}_{2}\right.$ or $\left.5 \% \mathrm{O}_{2}\right)$ (Phase I) were further cultured for up to two weeks (Phase II) in chondrogenic medium at the same or at interchanged oxygen percentages (that is, from $5 \%$ to $19 \% \mathrm{O}_{2}$ or from $19 \%$ to $5 \% \mathrm{O}_{2}$ ) (Figure 1). For the HIF-1 $\alpha$ inhibition experiments, pellets generated by cells from three donors after two weeks of culture at $19 \% \mathrm{O}_{2}$ were subsequently exposed to $5 \% \mathrm{O}_{2}$ and cultured for six hours or three days in chondrogenic medium supplemented with $5 \mu \mathrm{M}$ cadmium chloride $\left(\mathrm{CdCl}_{2}\right.$, SIGMA) [28].
Resulting tissues were analyzed histologically, immunohistochemically, biochemically and via scanning electronic microscopy to determine the quality of generated tissue, anabolic and catabolic cell functions and collagen fibril organization.

\section{Pellet characterization}

\section{Biochemical analyses}

For the determination of the glycosaminoglycan (GAG) and DNA contents, pellets were digested with protease $\mathrm{K}(0.5 \mathrm{ml}$ of $1 \mathrm{mg} / \mathrm{ml}$ protease $\mathrm{K}$ in $50 \mathrm{mM}$ Tris with 1 $\mathrm{mM}$ EDTA, $1 \mathrm{mM}$ iodoacetamide, and $10 \mu \mathrm{g} / \mathrm{ml}$ pepstatin-A for 15 hours at $56^{\circ} \mathrm{C}$ ) as previously described [29]. GAG contents of pellets were measured spectrophotometrically using the dimethylmethylene blue (DMMB) assay [30]. The DNA amount was measured spectrofluorometrically using the CyQUANT ${ }^{\circ}$ Kit (Molecular Probes, Eugene, OR, USA) following the kit's instruction. GAG contents were reported as $\mu \mathrm{g}$ GAG/ $\mu \mathrm{g}$ DNA.

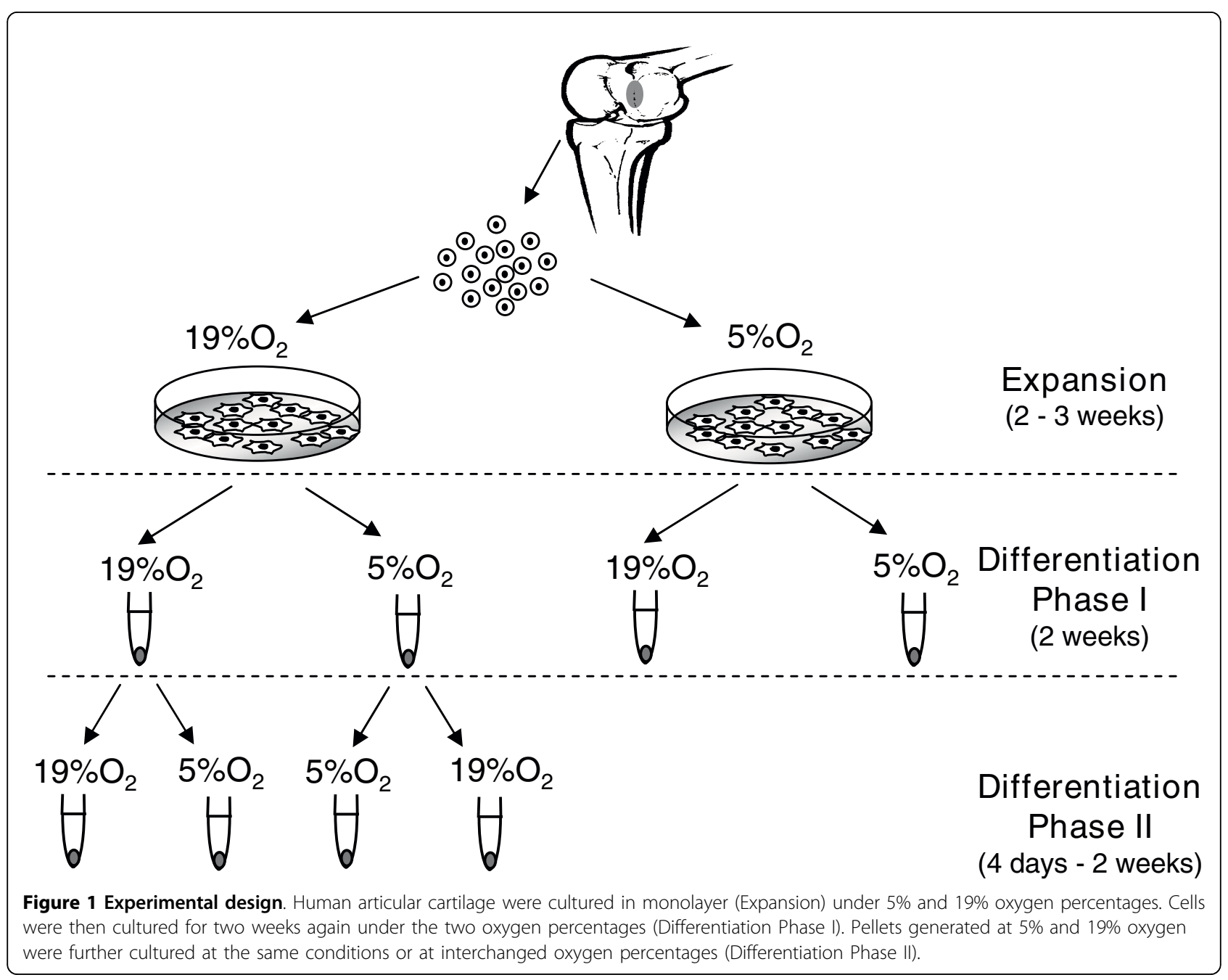




\section{Measurement of $\left[{ }^{35} \mathrm{~S}_{\mathrm{SO}} \mathrm{O}_{4}\right.$ and $\left.{ }^{3} \mathrm{H}\right]$ proline incorporation}

The proteoglycan and collagen synthesis of pellets were measured by assessing the incorporation of $\left({ }^{35} \mathrm{~S} \mathrm{SO}_{4}\right.$ and $\left({ }^{3} \mathrm{H}\right)$ proline for a period of $24 \mathrm{~h}$ as described previously [31]. Briefly, pellets were incubated in the presence of both $\left({ }^{35} \mathrm{~S}\right) \mathrm{SO}_{4}(1 \mu \mathrm{Ci} /$ culture $)$ to label proteoglycans and $\left({ }^{3} \mathrm{H}\right)$ proline $(1.5 \mu \mathrm{Ci} /$ culture $)$ to label collagen. For the assessment of the released ECM fraction, radiolabeled proteoglycan and collagen were precipitated overnight at $4^{\circ} \mathrm{C}$ using respectively $100 \%$ ethanol and $70 \%$ ammonium sulphate and subsequently, resuspended in $4 \mathrm{M}$ guanidine hydrochloride or $10 \%$ sodium dodecyl sulphate in Tris buffer $(0.1 \mathrm{M}, \mathrm{pH}$ 7.0) respectively for proteoglycan and collagen. For the assessment of the incorporated ECM fraction, tissue pellets were digested with protease $\mathrm{K}$ as previously described. The incorporation of $\left({ }^{35} \mathrm{~S}\right) \mathrm{SO}_{4}$ and $\left({ }^{3} \mathrm{H}\right)$ proline in culture pellet and in conditioned medium was measured in a Packard $\beta$-liquid scintillation counter with scintillation fluid (Ultima Gold, Perkin Elmer, Schwerzenbach, Switzerland). The amount of synthesised molecules was normalized to the DNA content of the tissue.

\section{Histological and immunohistochemical analyses}

Pellets were fixed in $4 \%$ formalin, embedded in paraffin and cross-sectioned ( $5 \mu \mathrm{m}$ thick sections). The sections were stained with Safranin O for sulfated GAG and processed for immunohistochemistry to visualize type II collagen (II-II6B3, Hybridoma Bank, University of Iowa, Iowa City, IA, USA), as described in Grogan et al. [32] and type II collagen fragments according to Roy-Beaudry et al. [33].

\section{Electronic microscopy (SEM)}

Images obtained from both scanning electron microscopy (SEM) and transmission electron microscopy (TEM) were used for the structural analysis of collagen fibrils. Pellet samples were glued onto a Teflon disc with a fiveminute curing epoxy glue (Devcon Epoxy, ITW Brands, Wood Dale, IL, USA). After which, the mounted specimens were placed in a vibratory microtome (VT $1000 \mathrm{E}$, Leica, Heidelberg, Germany) to trim off the outermost, approximately $150 \mu \mathrm{m}$ thick cartilage layer parallel to the support surface to minimize inhomogenities across the surface among samples. The surface layer of the adult healthy and OA cartilage was examined without any modification. The samples were then prepared for SEM and TEM analysis as previously described [34]. For TEM analysis, the samples were further homogenised into small pieces in order to isolate single collagen fibrils.

\section{Image analysis}

Quantitative data on the collagen fibril organization were obtained using the Image Processing Library \& Toolbox (IPLT) image analysis software package (Basel, Switzerland) [35]. A Canny edge detection algorithm [36], followed by a skeletonization algorithm [37] was applied to identify the collagen fibrils. The skeletonized data were subjected to an algorithm identifying the end points and intersections of the skeleton. Using this information, the individual line segments were identified and analyzed. Finally, the following parameters were determined from each pellet condition: (i) the bending ratio, calculated as the mean-squared end-to-end distance divided by the mean-squared contour length and (ii) the persistence length, calculated using a previously described model [38]. Both these parameters were required to correlate the linearity of the fibrils and length before branching of each individual fibril to its mechanical properties, respectively [39].

\section{Total RNA extraction and CDNA synthesis}

Total RNA of pellets was extracted using Trizol (Life Technologies, Basel, Switzerland) and the standard single-step acid-phenol guanidinium method. RNA was treated with DNAseI using the DNA-free ${ }^{\mathrm{TM}}$ Kit (Ambion, Austin, Texas) and quantified spectrometrically. cDNA was generated from $3 \mu \mathrm{g}$ of RNA by using $500 \mu \mathrm{g} / \mathrm{ml}$ random hexamers (Promega AG Dübendorf, Switzerland) and $1 \mu \mathrm{l}$ of $50 \mathrm{U} / \mathrm{ml}$ Stratascript ${ }^{\mathrm{TM}}$ reverse transcriptase (Stratagene, Amsterdam, NL), in the presence of dNTPs. Real-time RT-PCR reactions were performed and monitored using the ABI Prism 7700 Sequence Detection System (Perkin-Elmer/Applied Biosystems, Rotkreuz, Switzerland). Cycle temperatures and times as well as primers and probes used for the reference gene (18-S rRNA) and the genes of interest (collagen type II and aggrecan) were as previously described [40]. Assays on-Demand (Applied Biosystem) were used to measure the expression of $M M P-1$ (Hs00233958_m1), MMP-2 (Hs00234422_m1), MMP-9 (Hs00234579_m1) and MMP-13 (Hs00233992_m1). For each cDNA sample, the threshold cycle $(\mathrm{Ct})$ value of each target sequence was subtracted to the $\mathrm{Ct}$ value of $18-S$ rRNA, to derive $\Delta \mathrm{Ct}$. The level of gene expression was calculated as $2^{\Delta \mathrm{Ct}}$. Each sample was assessed at least in duplicate for each gene of interest.

\section{Quantification of released matrix metalloproteinases}

Matrix metalloproteinases (MMP) were quantified in media collected from cultured pellets by using the MultiAnalyte Profiling MMP base Kit (Fluorokine ${ }^{\circledast}$ MAP: LMP000) complemented with the specific MMPs (MMP-1: LMP901; MMP-3: LMP513; MMP-9: LMP911; MMP-13: LMP511, R\&D Systems, Minneapolis, MN, USA). The assay was performed on a Luminex $100^{\mathrm{TM}}$ analyzer (Austin, Texas, USA) following the manufacturer's instructions. The amount of released MMPs was normalized to the DNA content of the tissue.

\section{Statistical analysis}

For each analysis, triplicate pellets for each condition and donor were assessed. Statistical evaluation was 
performed using SPSS software version 7.5 software (SPSS, Sigma Stat, Erkrath, Germany). Values are presented as mean \pm standard deviation (SD). Differences between groups were assessed by Mann Whitney tests. Differences in the persistence length and bending ratio of collagen fibrils from different conditions were assessed by one-way analysis of variance (ANOVA) with Bonferroni post hoc test. Values of $P<0.05$ were considered statistically significant.

\section{Results}

\section{Chondrogenic differentiation of HAC cultured under different oxygen percentages}

HAC were initially cultured in monolayer with expansion medium at $5 \%$ or $19 \% \mathrm{O}_{2}$ and subsequently re-differentiated in three-dimensional pellets at the two different oxygen percentages (Phase I) (See Figure 1 for the experimental design). HAC proliferated at comparable rates (less than $5 \%$ variation in the number of doublings/day; data not shown) at the two oxygen conditions. Cells expanded at either oxygen percentage and subsequently differentiated at $19 \% \mathrm{O}_{2}$ produced tissues faintly stained for GAG and type II collagen (Figures 2A, I and 2II and $2 \mathrm{~B}$, I and 2II). Instead, reducing oxygen percentage during differentiation enhanced the amount of cartilaginous matrix accumulation, as evidenced by a qualitative increased size of the generated tissues (Figure 2A, low magnification), an increased intensity of Safranin $O$ and type II collagen stain (Figure 2A, B) and a statistically significant higher amount of GAG (3.4- and 3.1-fold for $\mathrm{HAC}$ expanded at $19 \%$ or $5 \% \mathrm{O}_{2}$ respectively) (Figure $2 \mathrm{C}$ ). Due to the fact that expansion at $5 \% \mathrm{O}_{2}$ did not influence the extent of HAC differentiation, further assessments were only performed with cells expanded at $19 \% \mathrm{O}_{2}$. In agreement with the histological and biochemical results, the RT-PCR analysis confirmed statistically significant higher expression of the cartilage specific genes type II collagen (86.6-fold) and aggrecan (8.5-fold) at $5 \% \mathrm{O}_{2}$ than at $19 \% \mathrm{O}_{2}$ after the Phase I differentiation culture (Figure 2D, E).

\section{Expression of catabolic mediators}

We then investigated the possible role of oxygen percentage in modulating the expression of catabolic mediators. Analysis of specific matrix metalloproteinases (that is, $M M P-1, M M P-2, M M P-9$ and $M M P-13$ ) by RT-PCR indicated that low oxygen percentage applied during the Phase I differentiation culture selectively down-regulated $M M P-1$ and $M M P-13$ mRNA expression (7.7- and 3.5-fold, respectively). $M M P-2$ mRNA was highly expressed and not modulated by the oxygen percentage. The expression of MMP-9 mRNA remained unaffected and was at the limit of detection at both oxygen percentages (Figure $3 \mathrm{~A}$ ).
The protein levels of MMP-1, -2, -9, -13 were assessed in the supernatant of pellet cultures at the end of Phase I. Consistent with the mRNA results, the amounts of MMP-1 and -13 released were reduced in the pellets cultured at $5 \% \mathrm{O}_{2}$ as compared to those cultured at $19 \%$ $\mathrm{O}_{2}$ (8.2- and 11.3-fold respectively). The protein expression levels of MMP-2 and -9 remained similar at the different oxygen percentages (Figure 3B).

\section{Effect of oxygen percentage on HAC anabolic and catabolic activity in pre-formed cartilaginous tissues}

We next investigated the influence of oxygen in anabolic (synthesis and accumulation of cartilaginous matrix proteins) and catabolic (MMPs expression, activity and degradation products) processes of pre-formed tissues. Pellets generated after two weeks of culture at $19 \% \mathrm{O}_{2}$ or $5 \% \mathrm{O}_{2}$ (Phase I) were subsequently cultured up to an additional two weeks (Phase II) at the same or at interchanged oxygen percentages (Figure 1).

Accumulation and synthesis of cartilaginous matrix proteins In agreement with the above described results, pellets cultured for four weeks (two weeks of Phase I and two weeks of Phase II) at $5 \% \mathrm{O}_{2}$ were more strongly stained for Safranin O and type II collagen, and accumulated larger amounts of GAG (4.0-fold) as compared to those cultured for the same time at $19 \% \mathrm{O}_{2}$ (Figure $4 \mathrm{~A}, \mathrm{~B}, \mathrm{C}$ ). Reducing oxygen percentage during Phase II for pellets cultured at 19\% during Phase I resulted in an improved quality of the cartilaginous tissues, as assessed by an increased accumulation of cartilaginous matrix positive for GAG and type II collagen (Figure 4A, B) and by a higher GAG content (3.3-fold) (Figure 4C). Conversely, increasing oxygen percentage during Phase II for pellets cultured at $5 \%$ during Phase I resulted in a reduced accumulation of cartilaginous matrix (Figure 4A, B) and GAG content (1.9-fold) (Figure 4C).

Results from the radiolabelling experiments indicated that similar amounts of total collagen and proteoglycan (that is, released + accumulated) were synthesized by pellets cultured for 18 days (two weeks of Phase I and four days of Phase II) at the two oxygen percentages. However, as compared to 19\% oxygen (Phase I and Phase II), the released fractions of these newly synthesized macromolecules by pellets cultured at $5 \% \mathrm{O}_{2}$ (Phase I and Phase II) were markedly and statistically significantly lower (2.0- and 2.9-fold respectively for collagen and proteoglycan), while the accumulated fractions were higher (2.1- and 6.6-fold respectively for collagen and proteoglycan). Consistent with the biochemical results, the culture at $5 \% \mathrm{O}_{2}$ during Phase II of tissues pre-formed at $19 \% \mathrm{O}_{2}$ during Phase I resulted in an augmented synthesis of collagen and proteoglycan (respectively by 2.7 - and 1.4-fold). In particular, the increased synthesis of the newly synthesized 


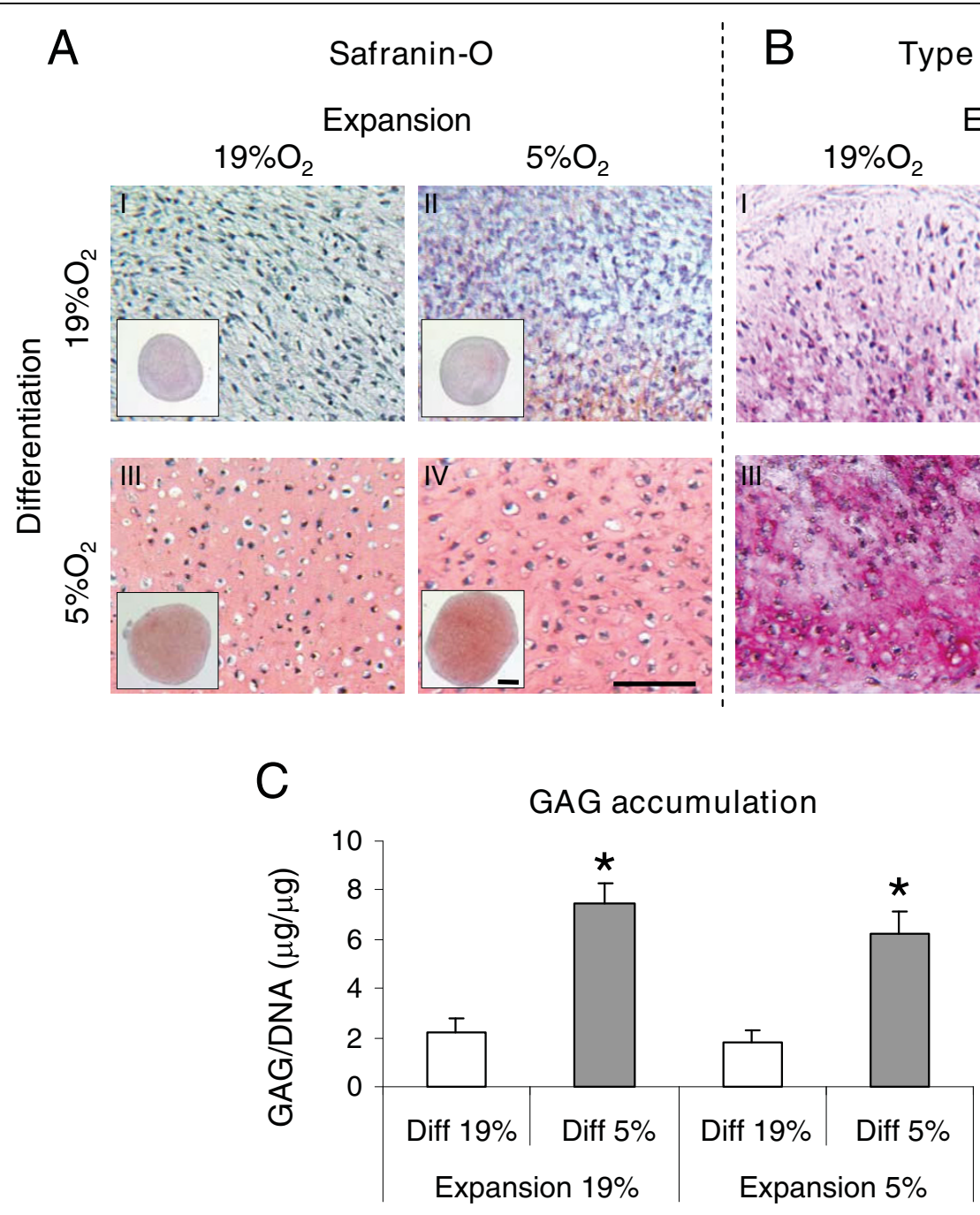

D

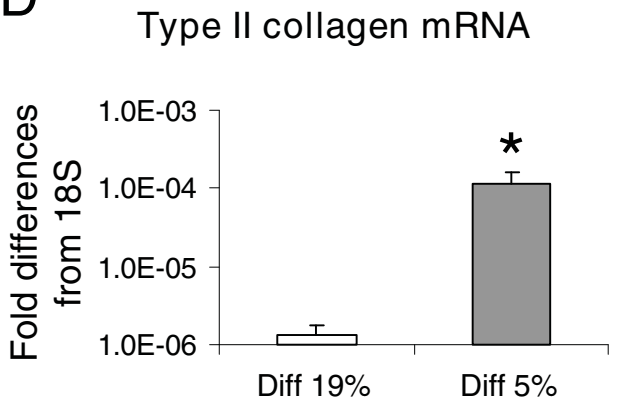

$\mathrm{E}$

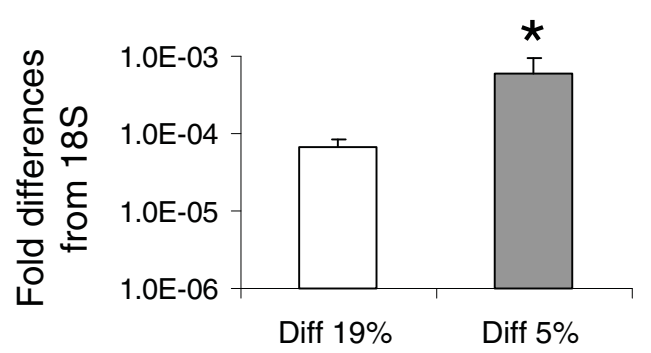

Figure 2 Anabolic response of HAC to different oxygen percentages during the expansion and differentiation Phase I. (A - B) Safranin $\mathrm{O}$ and type II collagen immunohistochemical stainings of representative tissues generated by human articular chondrocytes (HAC) expanded at 19\% (I and III) or 5\% (II and IV) oxygen and further cultured in pellets at 19\% (I and II) or 5\% (III and IV) oxygen. Bar = $100 \mu \mathrm{m}$. (C) Quantification of glycosaminoglycans (GAG) accumulated normalized to the amount of DNA. (D - E) Real time reverse transcription-polymerase chain reaction analysis of the expression of type /l collagen and aggrecan mRNA by HAC cultured in pellets at 19\% and 5\% $\mathrm{O}_{2}$. Levels are expressed as fold of difference from ribosomal 18S. For the gene expression analysis only expansion at $19 \% \mathrm{O}_{2}$ was considered. Values are mean $\pm \mathrm{SD}$ of measurements obtained from three independent experiments. ${ }^{*}=$ significantly different from the $19 \% \mathrm{O}_{2}$. 


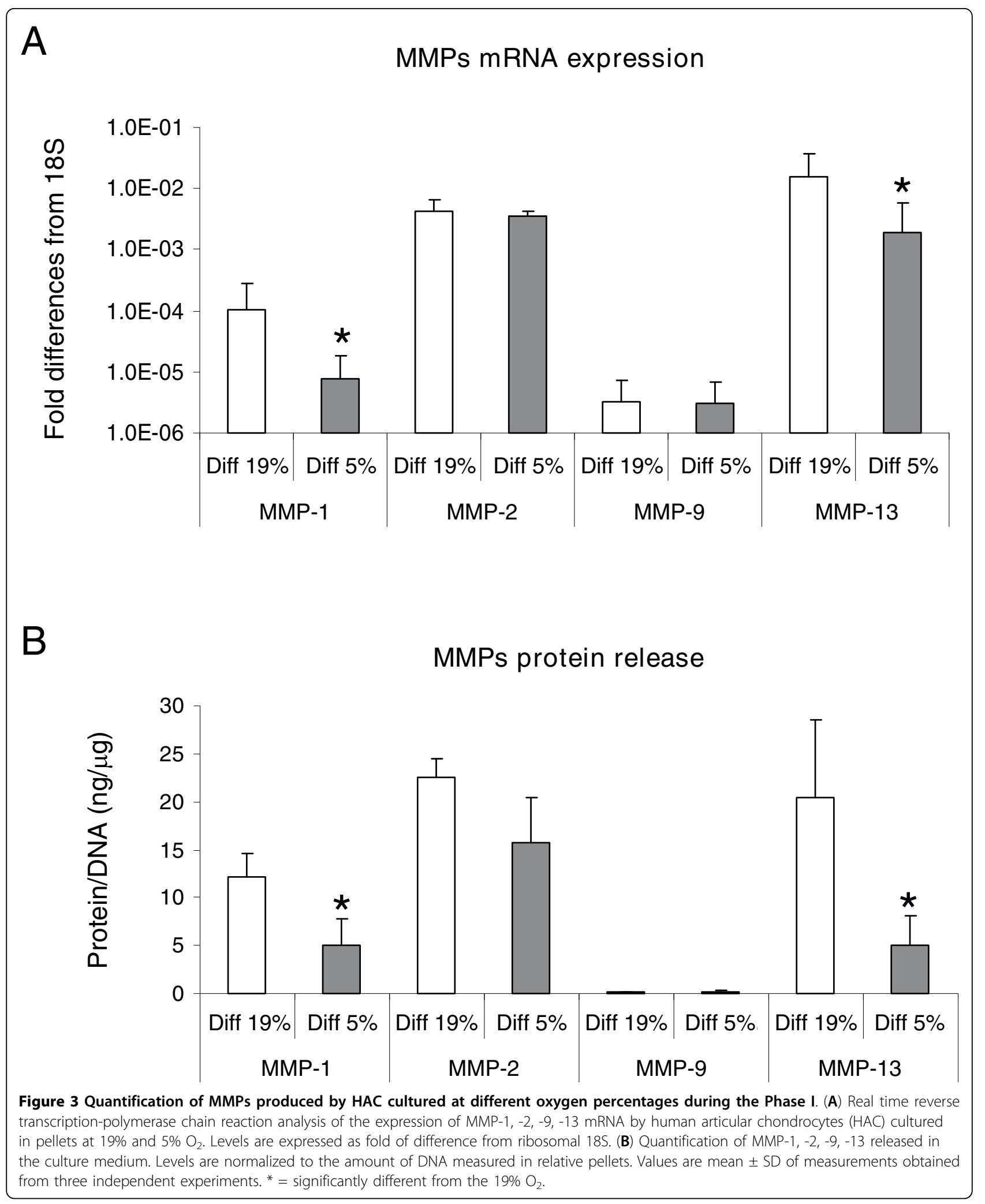




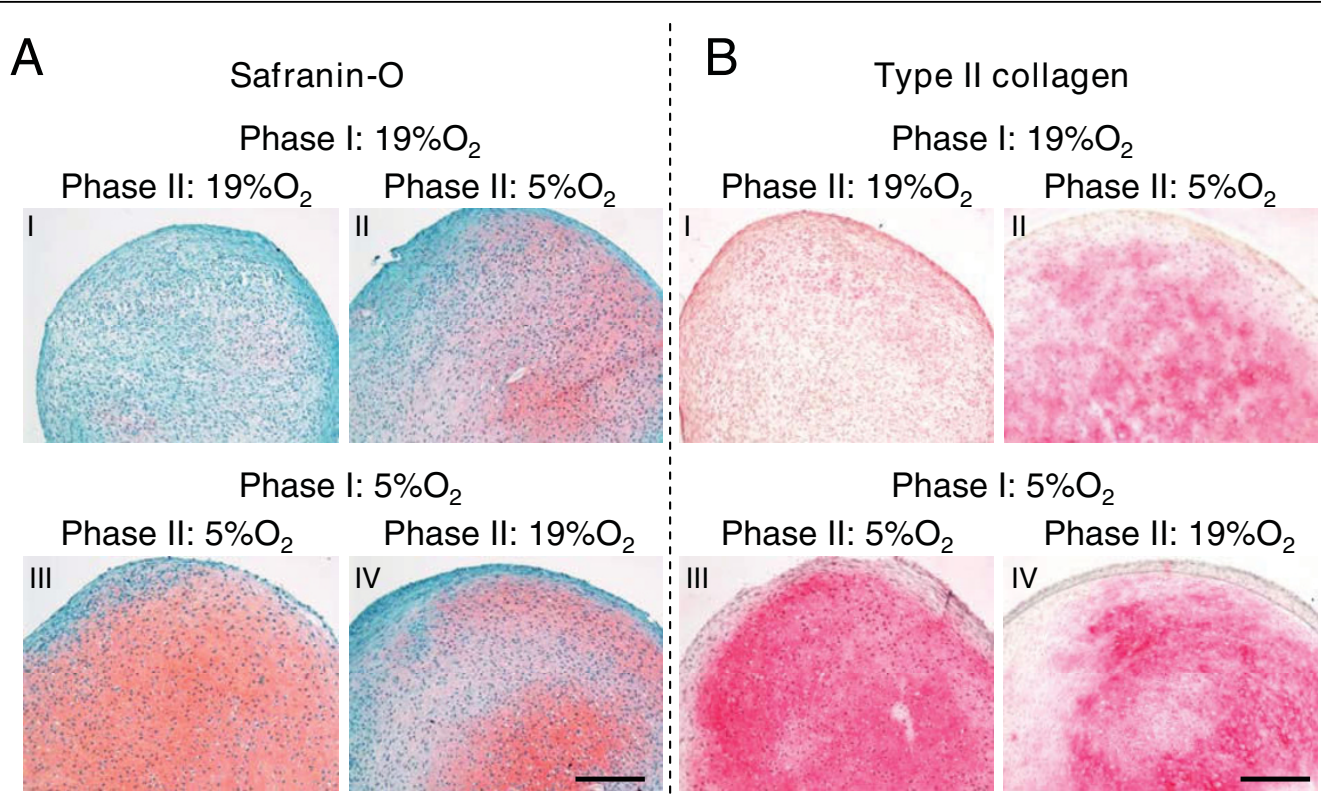

C

GAG accumulation
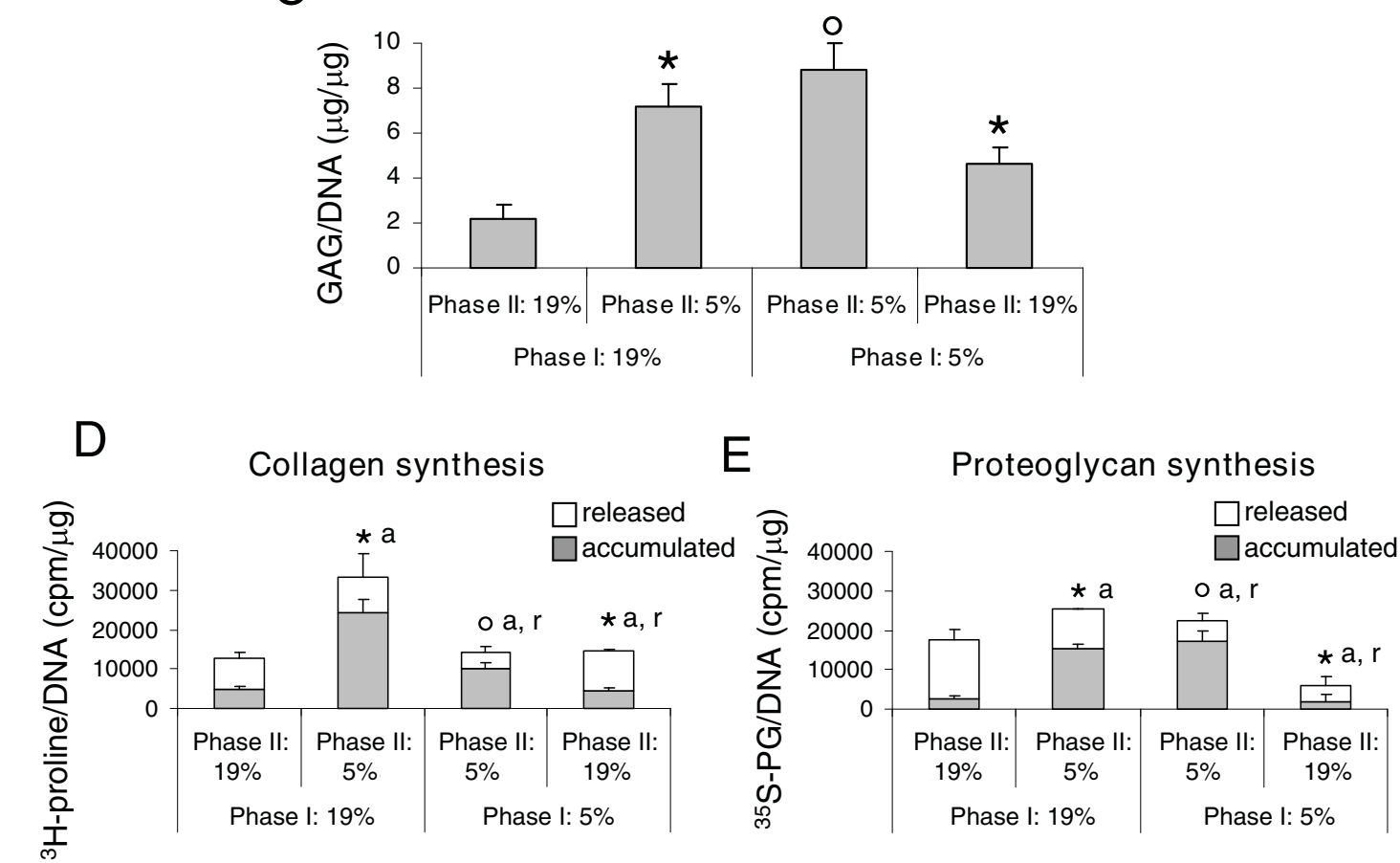

$\mathrm{E}$

Proteoglycan synthesis

Figure 4 Anabolic response of HAC to different oxygen percentages during differentiation Phase I and II. (A - B) Safranin O and type II collagen stainings of representative tissues generated by human articular chondrocytes (HAC) cultured in pellets for two weeks (Phase I) at 19\% (I and II) or 5\% (III and IV) oxygen and further cultured for two additionally weeks (Phase II) at 19\% (I and III) or 5\% (II and IV) oxygen. Bar = 100 um. (C) Quantification of glycosaminoglycans (GAG) accumulated in pellets cultured as described in (A - B) normalized to the amount of DNA. (D - E) Amounts of newly synthesized collagen (D) and proteoglycan (E) measured in pellets cultured for 18 days (two weeks of Phase I and four days of Phase II). The upper and lower parts of the columns represent the released and accumulated fractions respectively. Values are mean \pm SD of measurements obtained from two independent experiments. ${ }^{*}=$ significantly different from the group cultured with the same oxygen percentage in Phase I but with different oxygen tension in Phase $\mathrm{I}^{\circ}{ }^{\circ}=$ significantly different from the group cultured entirely at $19 \%$ O ${ }_{2}$ $\mathrm{a}=$ accumulated, $r=$ released. 
macromolecules was mainly reflected by an augmented accumulation (up to 5.9-fold). Instead, the culture at $19 \% \mathrm{O}_{2}$ during Phase II of tissues pre-formed at $5 \% \mathrm{O}_{2}$ during Phase I differently modulated the synthesis of the two extracellular matrix molecules: while a decreased accumulation (2.3-fold) and an increased released (2.6-fold) was measured for collagen, only a reduction of the accumulated fraction was demonstrated for proteoglycan (8.6-fold) (Figure 4D, E).

\section{MMPs production and activity}

Pellets cultured for four weeks (two weeks of Phase I and two weeks of Phase II) at $5 \% \mathrm{O}_{2}$ released lower amounts of MMP-1 and -13 (6.1- and 10.1-fold respectively) as compared to those cultured for the same time at $19 \% \mathrm{O}_{2}$. Culture at $5 \% \mathrm{O}_{2}$ during Phase II of tissues pre-formed at $19 \% \mathrm{O}_{2}$ during Phase I resulted in reduced production of both MMPs, though only MMP13 by statistically significant levels (by 1.8 -fold). Instead, culture at $19 \% \mathrm{O}_{2}$ during Phase II of pellets pre-formed at $5 \% \mathrm{O}_{2}$ during Phase I resulted in increased release of both MMP-1 and MMP-13 (4.0- and 6.2-fold respectively) (Figure 5A, B).

In order to assess whether the observed increased production of MMPs corresponded to an increased proteinase activity, pellets cultured for a total of four weeks at the different oxygen percentages were assessed immunohistochemically to detect the presence of type II collagen C-telopeptides, derived by MMP- 1 and -13 collagenolytic activity [33]. Analyses indicated that only the pellets formed at $5 \% \mathrm{O}_{2}$ during Phase I and subsequently cultured at $19 \% \mathrm{O}_{2}$ during Phase II were intensely stained for the type II collagen fragments (Figure 5C).

\section{Collagen fibril organization}

To determine whether increasing oxygen percentage during cultivation Phase II of tissues pre-formed at 5\% $\mathrm{O}_{2}$ would change the structure and arrangement of the collagen fibril network, pellets were qualitatively and quantitatively assessed via EM. Images indicated that the collagen fibrils of pellets cultured at $5 \% \mathrm{O}_{2}$ during Phase I and then for two weeks at $19 \% \mathrm{O}_{2}$ during Phase II were less linear than those of pellets cultured for four weeks at $5 \% \mathrm{O}_{2}$. Interestingly, a similar trend was also observed in the OA cartilage as compared to healthy cartilage samples (Figure 6A, B). In pellets, the collagen network was comprised of single fibrils with diameters ranging from 20 to $30 \mathrm{~nm}$. In healthy adult cartilage, the network contained bundled and twisted collagen fibrils three- to four-fold larger in diameter. Quantitative image analysis indicated that increasing the oxygen percentage during Phase II resulted in a significant reduction of persistence length as well as bending ratio ( $47.9 \%$ and $10.5 \%$ respectively). Interestingly, both parameters were higher in healthy as compared to OA tissues $(30.0 \%$ and $6.6 \%$ respectively for persistence length and bending ratio). Considerable decrease in persistence length and bending ratio would indicate softening and gradual deterioration of cartilage physiological function [39].

\section{Response to low oxygen under $\mathrm{CdCl}_{2}$-treatment}

To determine whether the observed pro-anabolic and anti-catabolic effects of low oxygen percentage are mediated by HIF-1 $\alpha$, HAC from three donors were precultured in pellets during Phase I at $19 \% \mathrm{O}_{2}$. During the subsequent culture Phase II, the pre-cultured pellets were maintained at $19 \% \mathrm{O}_{2}$ or exposed to $5 \% \mathrm{O}_{2}$, with or without treatment with $\mathrm{CdCl}_{2}$ for six hours or three days (Figure 7A). Following culture at low oxygen percentage, type II collagen mRNA was up-regulated to a higher extent after six hours (up to 33.0-fold; Figure 7B) than after three days (data not shown), while $M M P-1$ mRNA was down-regulated to a higher extent after three days (up to 65.5-fold; Figure 7C) than after six hours (data not shown). Supplementation of $\mathrm{CdCl}_{2}$ during this culture phase almost abrogated the aforementioned low $\mathrm{O}_{2}$-mediated effects, so that the expression of type II collagen and MMP-1 mRNA reached levels comparable to those of cells cultured at $19 \% \mathrm{O}_{2}$ for the corresponding times (Figure 7B, C).

\section{Discussion}

In this study we found that culture at low, more physiological (5\%) oxygen percentage has a dual role in HAC metabolism, namely to enhance the proteoglycan and collagen synthesis and at the same time to reduce the activity of two key catabolic enzymes involved in cartilage breakdown (that is, MMP-1 and MMP-13). As a consequence, $\mathrm{HAC}$ exposure to $19 \%$ oxygen reduced the de novo formation of cartilage tissue and induced degradation of pre-deposited collagen fibrils, leading to structural features similar to those found in osteoarthritic tissue. Interestingly, HAC appeared to be highly sensitive to the oxygen percentage applied during differentiation culture in pellets, but not during expansion in monolayers. The anti-anabolic and pro-catabolic effects mediated by low oxygen percentage were HIF1 $\alpha$-dependent, as assessed by specific inhibition of this factor by $\mathrm{CdCl}_{2}$ treatment.

The application of $5 \%$ oxygen percentage during the HAC monolayer expansion did not influence the proliferation rate and chondrogenic capacity of HAC. This is in contrast with results reported by Egli et al. [7], indicating that bovine articular chondrocytes expanded under hypoxic conditions generated tissues with higher amounts of cartilaginous matrix as compared to those expanded under normoxic conditions. The discrepancy between our results and those generated by Egli et al. [7] can be related to the different type of cells used (human vs bovine), the stage of cell de-differentiation 


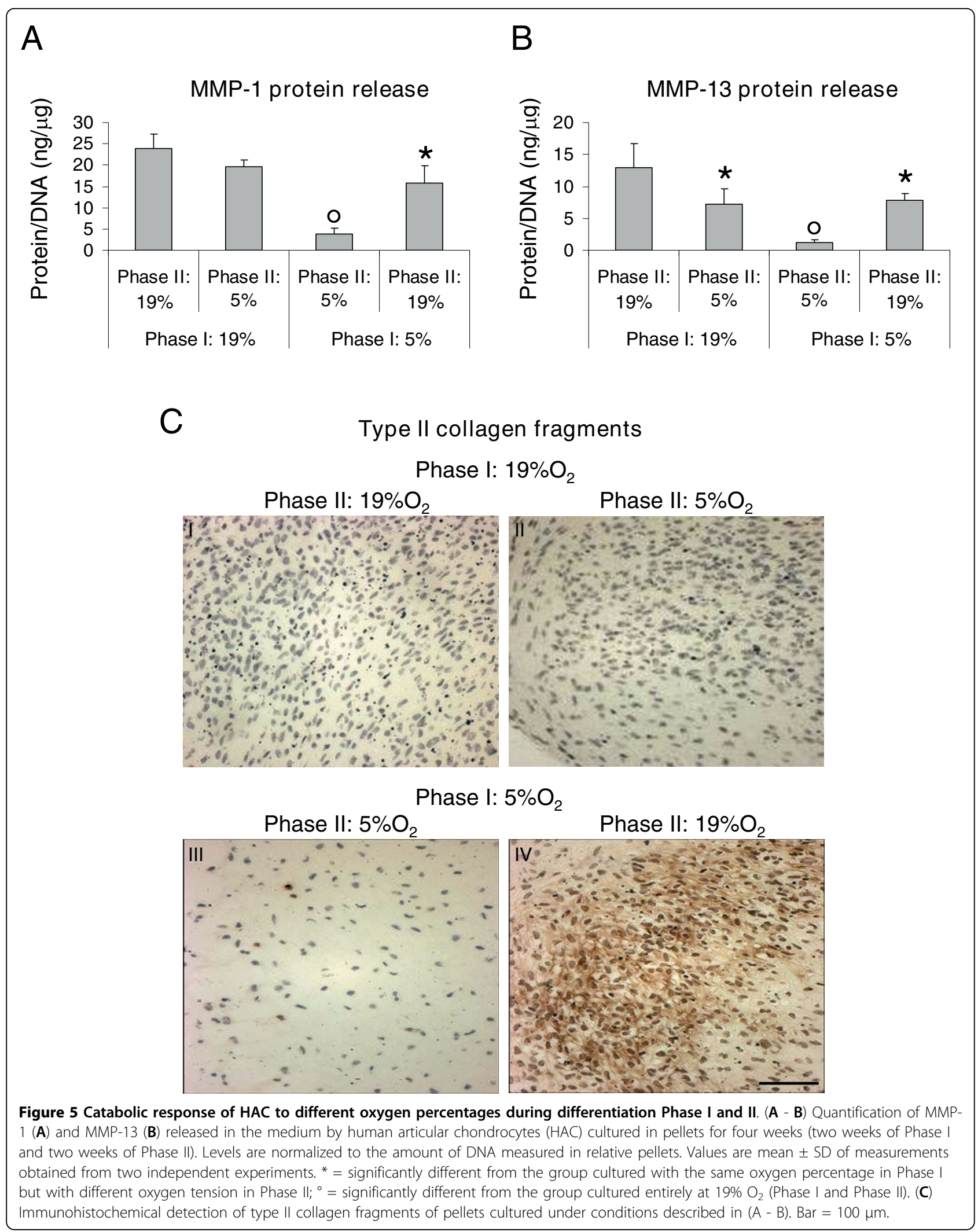




\section{SEM images}

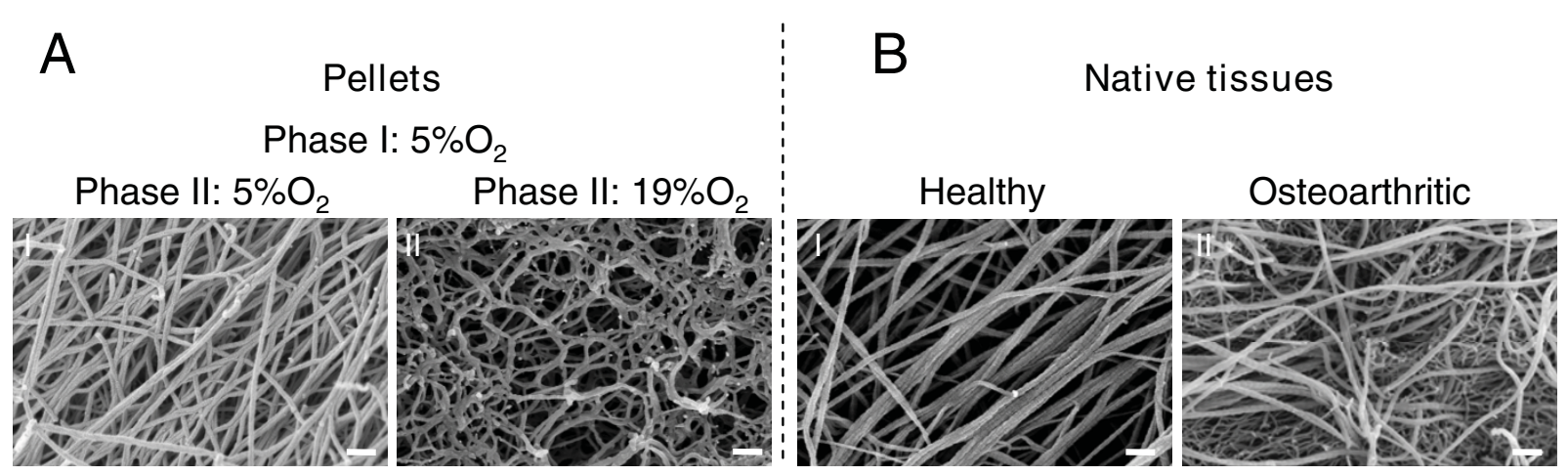

\section{Collagen structure}
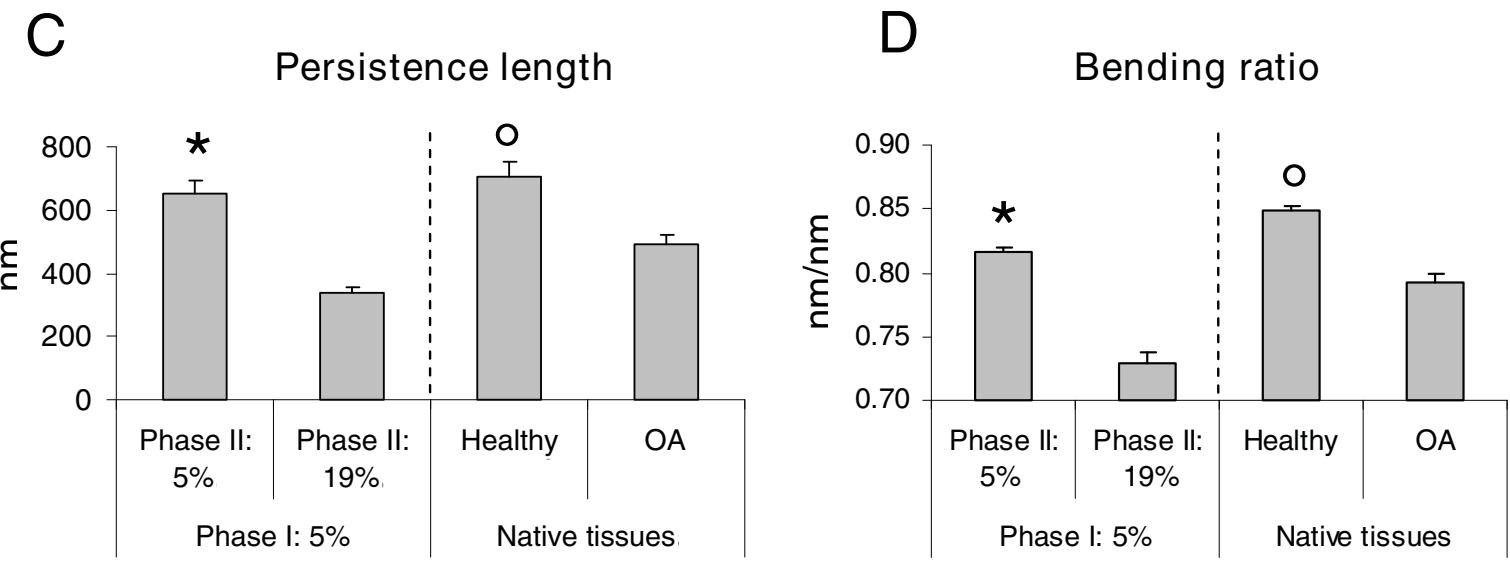

Figure 6 SEM images and structural analysis of extracellular collagen-fibrils from engineered, healthy and osteoarthritic cartilage samples. Representative scanning electron microscopy (SEM) images of (A) tissues generated by culturing human articular chondrocytes in pellets for four weeks (two weeks of Phase I and two weeks of Phase II) or (B) native human tissue biopsies from healthy or osteoarthritic (OA) cartilage. (C) Persistence length and (D) bending ratio assessment of the extracellular fibril network of engineered and native tissues. ${ }^{*}=$ significant different from $19 \% \mathrm{O}_{2} i^{\circ}=$ significant different from OA tissues.

(second passaged vs first passaged cells) and/or the specific oxygen percentage tested (5\% vs $1.5 \%$ ). Indeed, HAC culture at lower than $5 \%$ oxygen during expansion may lead to a benefit in their redifferentiation capacity, and remains to be investigated.

The influence of oxygen percentage during the denovo tissue formation was evaluated by culturing HAC in micromass pellets, a model commonly used to investigate in vitro cartilage development. Our results indicate that the application of $5 \%$ as compared to $19 \%$ oxygen percentage critically enhanced the chondrogenic capacity of HAC, as assessed by a greater accumulation of GAG and type II collagen. Similar responses to reduced oxygen percentage have been reported [9] using human nasal chondrocytes statically cultured in pellets for three days and subsequently transferred to a dynamic bioreactor system. We also investigated whether culture of chondrocytes at low oxygen percentage modulated the production of specific metalloproteinases involved in the degradation of extracellular matrix proteins. We observed that the expression of MMP-1 and MMP-13, both at mRNA and protein levels, was reduced in cells cultured at $5 \%$ as compared to $19 \%$ oxygen. Interestingly, MMP-1 (or collagenase-1) and/or MMP-13 (or collagenase-3) are among the enzymes expressed by human chondrocytes in degenerative 


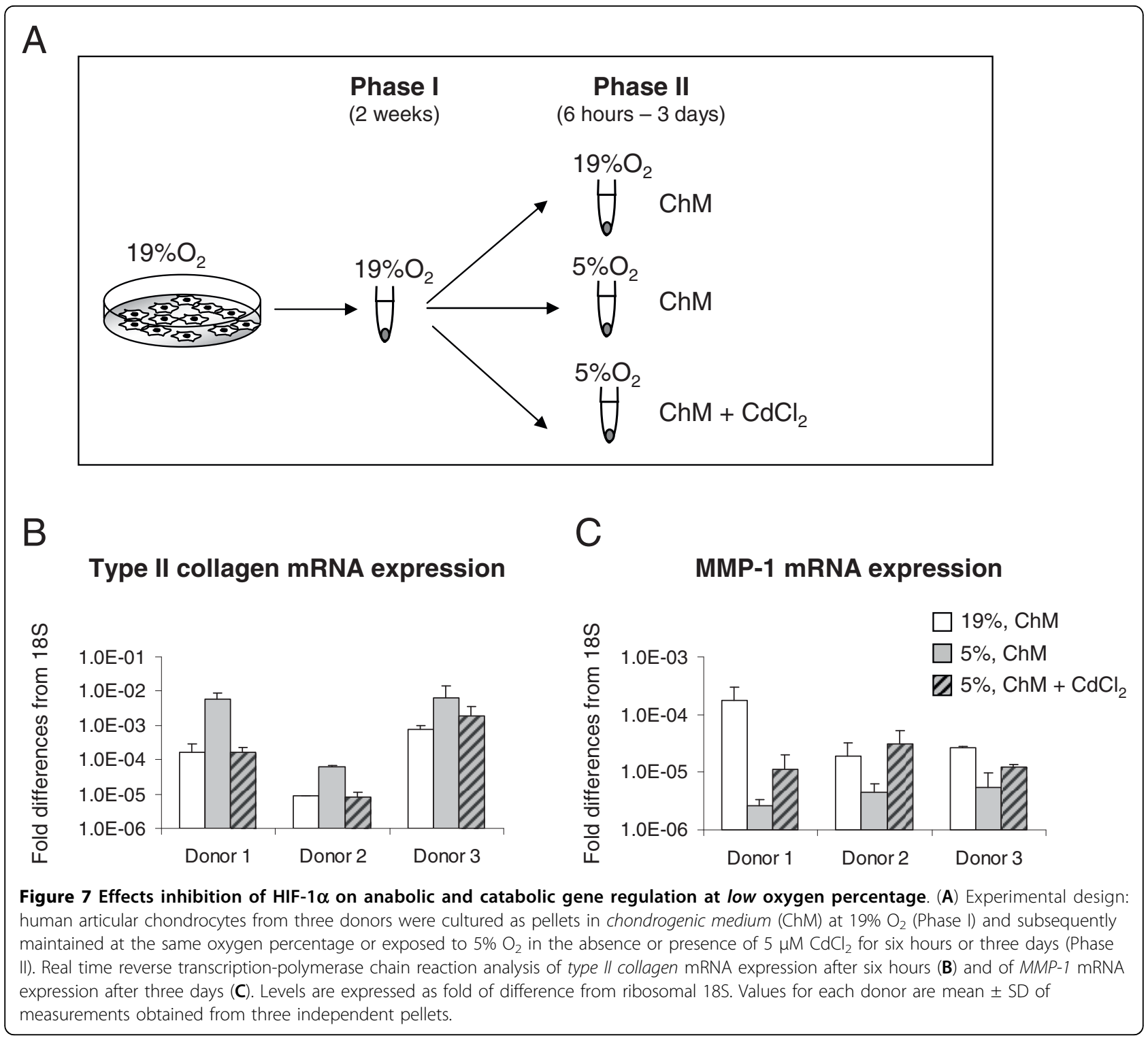

pathologies of cartilage, namely osteoarthritis and rheumatoid arthritis [41] and are thus thought to play a critical role in cartilage destruction. In particular, it has been shown that both MMPs are involved in the initial phase of type II collagen breakdown [42,43], and MMP13 is the collagenase with highest affinity for type II collagen [44]. However, the expression of other MMPs or degradative enzymes (for example, aggrecanases) not included in our study might also be regulated by culture at low oxygen tension.

Our results prompted us to hypothesize that different oxygen percentages could regulate not only cartilage generation, but also its further maturation and stability. We thus exposed tissues formed at the different oxygen percentages for two weeks (Phase I) to interchanged oxygen percentages in a subsequent culture phase
(Phase II). Results obtained from the radiolabelling experiments indicated that the exposure of tissues to $5 \%$ oxygen during Phase II induced higher synthesis and accumulation of collagen and proteoglycan. It remains to be assessed whether low oxygen percentages also enhance expression of molecules involved in stabilization of the newly synthesized extracellular matrix components (for example, decorin, fibromodulin, link protein, type IX collagen) [45]. Importantly, the presence of type II collagen cleavage products, indicative of MMP activity, was immunohistochemically detected [33] only in the pellets pre-formed at $5 \%$ oxygen (Phase I) and subsequently cultured for additional two weeks at 19\% oxygen (Phase II). These results, together with the observed enhanced expression of MMP-1 and -13 at $19 \%$ oxygen, strongly indicate a direct involvement of 
oxygen in regulating the MMP-mediated breakdown of cartilaginous tissues. The result that pellets entirely cultured at $19 \% \mathrm{O}_{2}$ negatively stained for type II collagen fragments could be explained by the insufficient accumulation of the MMP substrate (that is, type II collagen) during the initial cultivation Phase I.

The presence of type II collagen fragments correlated well with the branched/tangled collagen fibril organization and decreased values of bending ratio and persistence length in pellets exposed to $19 \%$ oxygen. This could possibly result from an increased enzymatic cleavage of the extracellular matrix molecules by specific MMPs. Conclusively, increased activity of catabolic enzymes is affecting the collagen fibril network that exhibits lower values of bending ratio and persistence length. Based on this correlation, both parameters could potentially represent valuable markers for determining the degree of collagen deterioration. Exposure of cartilage tissues formed at physiological oxygen percentages to higher oxygen levels resembled degradation events occurring during the progression of OA, where, following initial pathologic events, the normal oxygen gradients break down [6]. Therefore, our tissue engineering model would be instrumental to investigation of the evolution of cartilage damage following alteration of the oxygen levels and to assess the effect of possible therapeutic targets.

The observed pro-anabolic and anti-catabolic effects of low oxygen culture were mediated by the hypoxia inducible signaling pathway, since reduction of the oxygen percentage did not regulate type II collagen and MMP-1 mRNA expression in the presence of the HIF-1 $\alpha$ inhibitor cadmium chloride $\left(\mathrm{CdCl}_{2}\right)$ [28]. While the importance of HIF- $1 \alpha$ in modulating the expression/synthesis of cartilage-specific genes was recently addressed [28-46], the involvement of this factor in the oxygendependent modulation of catabolic genes, recently reported for porcine pulmonary artery endothelial and smooth muscle cells [47], has not been previously postulated for HAC.

\section{Conclusions}

The present study demonstrates that low oxygen percentage applied during the differentiation phases of human articular chondrocyte culture enhances cell biosynthetic activity as well as reduces the activity of catabolic enzymes known to play key roles in the breakdown of cartilage matrix during degenerative pathologies. These findings indicate that regulation of oxygen percentages during in vitro culture could be used to improve the generation of functional cartilage substitutes, and thus prompt the development of tools enabling accurate control of oxygen levels for tissues of clinically relevant size [48]. Moreover, modulation of oxygen tension in cultured HAC may be used as a tool to model and study in vitro pathophysiological events occurring in osteoarthritis. Finally, following such investigations, the identification of innovative strategies to maintain local in vivo oxygen percentages to defined levels could represent a powerful tool for preventing the progression of degenerative cartilage diseases.

\section{Abbreviations}

ANOVA: analysis of variance; CDNA: complementary deoxyribonucleic acid; $\mathrm{CO}_{2}$ : carbon dioxide; $\mathrm{Ct}$ : threshold cycle; DMEM: Dulbecco's modified Eagle's medium; DMMB: dimethylmethylene blue; dNTP: deoxyribonucleotide; ECM: extracellular matrix; EDTA: ethylenediaminetetraacetic acid; EM: electronic microscopy; GAG: glycosaminoglycans; HAC: human articular chondrocytes; HEPES: 4-(2hydroxyethyl)-1-piperazineethanesulfonic acid; HIF-1 $\alpha$ : hypoxia-inducible factor-1alpha; IPLT: Image Processing Library \& Toolbox; MMP: metalloproteinase; mRNA: messenger ribonucleic acid; $\mathrm{O}_{2}$ : oxygen; OA: osteoarthritis; PBS: phosphate buffered saline; RNA: ribonucleic acid; rRNA: ribosomal ribonucleic acid; RT-PCR: reverse-transcriptase polymerase chain reaction; SD: standard deviation; SEM: scanning electron microscopy; TEM: transmission electron microscopy; TGF $\beta$ 1: transforming growth factor beta-1.

\section{Acknowledgements}

We would like to acknowledge the European Union for financial support (STEPS; FP6-\#NMP3-CT-2005-500465) and the National Competence Center in Research (NCCR) program Nanoscale Science, awarded by the Swiss National Science Foundation, for support to Mr. M. Loparic. We are grateful to Mrs F. Wolf and Mrs D. Thuillard for their assistance with immunohistochemical processing, to Dr. Riccardo Gottardi from Department for Biophysical Engineering (Genova, Italy) for his assistance with EM analysis and Dr. M. Duggelin and Ms. Melanie Burkhardt for the imaging analysis. We thank Dr. Christgau from Nordic Immunology (Tilburg, NL) for the generous supply of the antibodies against type II collagen fragments.

\section{Author details}

'Departments of Surgery and of Biomedicine, University Hospital Basel, Hebelstrasse 20, Basel, 4031, Switzerland. ${ }^{2}$ M.E. Müller Institute for Structural Biology, Biozentrum University of Basel, Klingelbergstrasse 50/70, Basel, 4056, Switzerland. ${ }^{3}$ Department of Orthopaedic Surgery and Traumatology, Ospedale Regionale di Lugano, Via Tesserete 46, Lugano, 6900, Switzerland. ${ }^{4}$ Departments of Biomedicine and Neurology, University Hospital Basel, Hebelstrasse 20, Basel, 4031, Switzerland. ${ }^{5}$ Faculty of Dentistry and CHU Sainte-Justine, University of Montreal, 3175 Côte Sainte-Catherine, Montreal, H3T1C5, Canada.

\section{Authors' contributions}

SS participated in study conception and design, acquisition of data (biochemistry, histology, immunohistochemistry for type II collagen, RT-PCR analysis and cell culture), in the study design, in the interpretation of data and drafting the manuscript. ML participated in acquisition of the data (scanning electronic microscopy and image analysis) and in the interpretation of data. DW participated in study conception in the study design and revised the manuscript. ADS participated in analysis (image analysis). CC participated in study conception and provided the patient biopsies and their clinical data. RLPL participated in the development of the Luminex assays. FM participated in the acquisition of data

(immunohistochemistry for type II collagen fragments) and revised the manuscript. $A B$ and IM were responsible for study design, supervision of the experiments, interpretation of data and participated in writing the manuscript. All authors read and approved the final manuscript.

\section{Competing interests}

The authors declare that they have no competing interests.

Received: 28 September 2009 Revised: 9 February 2010 Accepted: 2 March 2010 Published: 2 March 2010 


\section{References}

1. Martin JA, Brown T, Heiner A, Buckwalter JA: Post-traumatic osteoarthritis: the role of accelerated chondrocyte senescence. Biorheology 2004, 41:479-491.

2. Martin JA, Buckwalter JA: Roles of articular cartilage aging and chondrocyte senescence in the pathogenesis of osteoarthritis. lowa Orthop J 2001, 21:1-7.

3. Malda J, Martens DE, Tramper J, van Blitterswijk CA, Riesle J: Cartilage tissue engineering: controversy in the effect of oxygen. Crit Rev Biotechnol 2003, 23:175-194.

4. Silver IA: Measurement of $\mathrm{pH}$ and ionic composition of pericellular sites Philos Trans R Soc Lond B Biol Sci 1975, 271:261-272.

5. Gonsalves M, Barker AL, Macpherson JV, Unwin PR, O'Hare D, Winlove CP: Scanning electrochemical microscopy as a local probe of oxygen permeability in cartilage. Biophys J 2000, 78:1578-1588.

6. Grimshaw MJ, Mason RM: Bovine articular chondrocyte function in vitro depends upon oxygen tension. Osteoarthritis Cartilage 2000, 8:386-392.

7. Egli RJ, Bastian JD, Ganz R, Hofstetter W, Leunig M: Hypoxic expansion promotes the chondrogenic potential of articular chondrocytes. J Orthop Res 2008, 26:977-985

8. Hansen U, Schunke M, Domm C, loannidis N, Hassenpflug J, Gehrke T, Kurz B: Combination of reduced oxygen tension and intermittent hydrostatic pressure: a useful tool in articular cartilage tissue engineering. J Biomech 2001, 34:941-949.

9. Malda J, van Blitterswijk CA, van Geffen M, Martens DE, Tramper J, Riesle J: Low oxygen tension stimulates the redifferentiation of dedifferentiated adult human nasal chondrocytes. Osteoarthritis Cartilage 2004, 12:306-313.

10. Nevo Z, Beit-Or A, Eilam Y: Slowing down aging of cultured embryonal chick chondrocytes by maintenance under lowered oxygen tension. Mech Ageing Dev 1988, 45:157-165.

11. Lane JM, Brighton CT, Menkowitz BJ: Anaerobic and aerobic metabolism in articular cartilage. J Rheumatol 1977, 4:334-342.

12. Murphy $C L$, Sambanis A: Effect of oxygen tension and alginate encapsulation on restoration of the differentiated phenotype of passaged chondrocytes. Tissue Eng 2001, 7:791-803.

13. Malda J, Brink van den P, Meeuwse P, Grojec M, Martens DE, Tramper J, Riesle J, van Blitterswijk CA: Effect of oxygen tension on adult articular chondrocytes in microcarrier bioreactor culture. Tissue Eng 2004, 10:987-994.

14. Marcus RE: The effect of low oxygen concentration on growth, glycolysis, and sulfate incorporation by articular chondrocytes in monolayer culture. Arthritis Rheum 1973, 16:646-656.

15. Saini S, Wick TM: Effect of low oxygen tension on tissue-engineered cartilage construct development in the concentric cylinder bioreactor. Tissue Eng 2004, 10:825-832.

16. Domm C, Schunke M, Christesen K, Kurz B: Redifferentiation of dedifferentiated bovine articular chondrocytes in alginate culture under low oxygen tension. Osteoarthritis Cartilage 2002, 10:13-22.

17. Kurz B, Domm C, Jin M, Sellckau R, Schunke M: Tissue engineering of articular cartilage under the influence of collagen I/III membranes and low oxygen tension. Tissue Eng 2004, 10:1277-1286.

18. Martinez I, Elvenes J, Olsen R, Bertheussen K, Johansen O: Redifferentiation of in vitro expanded adult articular chondrocytes by combining the hanging-drop cultivation method with hypoxic environment. Cell Transplant 2008, 17:987-996.

19. Murphy $\mathrm{CL}$, Sambanis $\mathrm{A}$ : Effect of oxygen tension on chondrocyte extracellular matrix accumulation. Connect Tissue Res 2001, 42:87-96.

20. Murphy $\mathrm{CL}$, Polak JM: Control of human articular chondrocyte differentiation by reduced oxygen tension. J Cell Physiol 2004 199:451-459.

21. Nevo Z, Horwitz AL, Dorfmann A: Synthesis of chondromucoprotein by chondrocytes in suspension culture. Dev Biol 1972, 28:219-228.

22. Scherer K, Schunke M, Sellckau R, Hassenpflug J, Kurz B: The influence of oxygen and hydrostatic pressure on articular chondrocytes and adherent bone marrow cells in vitro. Biorheology 2004, 41:323-333.

23. Brighton $\mathrm{CT}$, Lane $\mathrm{JM}$, Koh JK: In vitro rabbit articular cartilage organ model. II. 35S incorporation in various oxygen tensions. Arthritis Rheum 1974, 17:245-252.

24. Clark CC, Tolin BS, Brighton CT: The effect of oxygen tension on proteoglycan synthesis and aggregation in mammalian growth plate chondrocytes. J Orthop Res 1991, 9:477-484.
25. Obradovic B, Carrier RL, Vunjak-Novakovic G, Freed LE: Gas exchange is essential for bioreactor cultivation of tissue engineered cartilage. Biotechnol Bioeng 1999, 63:197-205.

26. Ysart GE, Mason RM: Responses of articular cartilage explant cultures to different oxygen tensions. Biochim Biophys Acta 1994, 1221:15-20.

27. Barbero A, Grogan S, Schafer D, Heberer M, Mainil-Varlet $P$, Martin I: Age related changes in human articular chondrocyte yield, proliferation and post-expansion chondrogenic capacity. Osteoarthritis Cartilage 2004, 12:476-484.

28. Duval E, Leclercq S, Elissalde JM, Demoor M, Galéra P: Hypoxia-inducible factor-a inhibits the fibroblast-like markers type I and type III collagen during hypoxia-induced chondrocyte redifferentiation: Hypoxia not only induces type II collagen and aggrecan, but it also inhibits type I and type III collagen in the hypoxia-inducible factor 1a-dependent redifferentiation of chondrocytes. Arthritis Rheum 2009, 60:3038-3048.

29. Hollander AP, Heathfield TF, Webber C, Iwata Y, Bourne R, Rorabeck C, Poole AR: Increased damage to type II collagen in osteoarthritic articular cartilage detected by a new immunoassay. J Clin Invest 1994, 93:1722-1732.

30. Farndale RW, Buttle DJ, Barrett AJ: Improved quantitation and discrimination of sulphated glycosaminoglycans by use of dimethylmethylene blue. Biochim Biophys Acta 1986, 883:173-177.

31. Waldman SD, Couto DC, Grynpas MD, Pilliar RM, Kandel RA: A single application of cyclic loading can accelerate matrix deposition and enhance the properties of tissue-engineered cartilage. Osteoarthritis Cartilage 2006, 14:323-330.

32. Grogan SP, Rieser F, Winkelmann V, Berardi S, Mainil-Varlet P: A static, closed and scaffold-free bioreactor system that permits chondrogenesis in vitro. Osteoarthritis Cartilage 2003, 11:403-411.

33. Roy-Beaudry M, Martel-Pelletier J, Pelletier JP, M'Barek KN, Christgau S, Shipkolye F, Moldovan F: Endothelin 1 promotes osteoarthritic cartilage degradation via matrix metalloprotease 1 and matrix metalloprotease 13 induction. Arthritis Rheum 2003, 48:2855-2864.

34. Stolz M, Gottardi R, Raiteri R, Miot S, Martin I, Imer R, Staufer U, Raducanu A Duggelin M, Baschong W, Daniels AU, Friederich NF, Aszodi A, Aebi U: Early detection of aging cartilage and osteoarthritis in mice and patient samples using atomic force microscopy. Nat Nanotechnol 2009, 4:186-192.

35. Philippsen A, Schenk AD, Signorelli GA, Mariani V, Berneche S, Engel A: Collaborative EM image processing with the IPLT image processing library and toolbox. J Struct Biol 2007, 157:28-37.

36. Canny JF: A computational approach to edge detection. IEEE Trans Pattern Anal Mach Intell 1986, 8:679-698.

37. Gonzalez RC, Woods RE: Digital Image Processing Prentice Hall, Inc., USA, 32007.

38. Hagerman PJ: Flexibility of DNA. Annu Rev Biophys Biophys Chem 1988, 17:265-286.

39. Raub CB, Unruh J, Suresh V, Krasieva T, Lindmo T, Gratton E, Tromberg BJ, George SC: Image correlation spectroscopy of multiphoton images correlates with collagen mechanical properties. Biophys J 2008, 94:2361-2373.

40. Jakob M, Demarteau O, Schafer D, Hintermann B, Dick W, Heberer M, Martin I: Specific growth factors during the expansion and redifferentiation of adult human articular chondrocytes enhance chondrogenesis and cartilaginous tissue formation in vitro. J Cell Biochem 2001, 81:368-377.

41. Burrage PS, Mix KS, Brinckerhoff CE: Matrix metalloproteinases: role in arthritis. Front Biosci 2006, 11:529-543.

42. Dahlberg L, Billinghurst RC, Manner P, Nelson F, Webb G, lonescu M, Reiner A, Tanzer M, Zukor D, Chen J, van Wart HE, Poole AR: Selective enhancement of collagenase-mediated cleavage of resident type II collagen in cultured osteoarthritic cartilage and arrest with a synthetic inhibitor that spares collagenase 1 (matrix metalloproteinase 1). Arthritis Rheum 2000, 43:673-682

43. Wu W, Billinghurst RC, Pidoux I, Antoniou J, Zukor D, Tanzer M, Poole AR: Sites of collagenase cleavage and denaturation of type II collagen in aging and osteoarthritic articular cartilage and their relationship to the distribution of matrix metalloproteinase 1 and matrix metalloproteinase 13. Arthritis Rheum 2002, 46:2087-2094.

44. Reboul P, Pelletier JP, Tardif G, Cloutier JM, Martel-Pelletier J: The new collagenase, collagenase- 3 , is expressed and synthesized by human chondrocytes but not by synoviocytes. A role in osteoarthritis. J Clin Invest 1996, 97:2011-2019. 
45. Poole AR, Kojima T, Yasuda T, Mwale F, Kobayashi M, Laverty S:

Composition and structure of articular cartilage: a template for tissue repair. Clin Orthop Relat Res 2001, 391:26-33.

46. Pfander D, Cramer T, Schipani E, Johnson RS: HIF-1alpha controls extracellular matrix synthesis by epiphyseal chondrocytes. J Cell Sci 2003, 116:1819-1826.

47. Ye H, Zheng Y, Ma W, Ke D, Jin X, Liu, Wang D: Hypoxia down-regulates secretion of MMP-2, MMP-9 in porcine pulmonary artery endothelial and smooth muscle cells and the role of HIF-1. J Huazhong Univ Sci Technolog Med Sci 2005, 25:382-384.

48. Wendt D, Stroebel S, Jakob M, John GT, Martin I: Uniform tissues engineered by seeding and culturing cells in $3 \mathrm{D}$ scaffolds under perfusion at defined oxygen tensions. Biorheology 2006, 43:481-488.

doi:10.1186/ar2942

Cite this article as: Ströbel et al: Anabolic and catabolic responses of human articular chondrocytes to varying oxygen percentages. Arthritis Research \& Therapy 2010 12:R34.

\section{Submit your next manuscript to BioMed Central} and take full advantage of:

- Convenient online submission

- Thorough peer review

- No space constraints or color figure charges

- Immediate publication on acceptance

- Inclusion in PubMed, CAS, Scopus and Google Scholar

- Research which is freely available for redistribution

Submit your manuscript at www.biomedcentral.com/submit 